http://dx.doi.org/10.30681/real.v11i2.2555

\title{
AS POSIÇÕES SUJEITO PROFESSOR E ALUNO EM O SORRISO DE MONALISA E CLUBE DO IMPERADOR
}

\author{
Kamila de Aquino SANTOS (UEG) ${ }^{1}$ \\ Karla Murielle de Aquino SANTOS (UEG) ${ }^{2}$ \\ Fernanda Surubi FERNANDES (UEG/UNEMAT) ${ }^{3}$
}

\begin{abstract}
Resumo: A relação professor-aluno está no cerne do ensino-aprendizagem. Assim, compreender como se dá esse processo faz parte de compreender as posições sujeitos que se estabelecem através de um discurso pedagógico voltado para a legitimação da autoridade docente (ORLANDI, 2009). Nessa direção, o objetivo desse estudo é compreender essa relação através da análise de dois filmes que retratam a relação professor-aluno. Os filmes são O Clube do Imperador dirigido por Michael Hoffman (2002) e O Sorriso de Monalisa sob direção de Mike Newell (2004). Possui como base teórica a Análise de Discurso de linha francesa, tendo como precursores Eni Pulccinelli Orlandi (2009), no Brasil e Michel Pêcheux (2007), na França. Além desses autores, baseamos em Fedatto e Machado (2007) para compreender o funcionamento discursivo da relação professor-aluno materializado nas cenas analisadas. E Milanez e Bittencourt (2012), que apresentam a noção de materialidade fílmica.
\end{abstract}

Palavras-chave: Análise de discurso. Discurso fílmico. Ensino.

\begin{abstract}
The teacher-student relationship is at the heart of teaching-learning. Thus, understanding how this process takes place is part of understanding the subject positions that are established through a pedagogical discourse aimed at legitimizing the teaching authority (ORLANDI, 2009). In this direction, the objective of this study is to understand this relationship through the analysis of two films that portray the teacher-student relationship. The films are The Emperor's Club directed by Michael Hoffman (2002) and The Smile of Monalisa directed by Mike Newell (2004). It has as its theoretical basis the Discourse Analysis of French line, having as precursors Eni Pulccinelli Orlandi (2009) in Brazil and Michel Pêcheux (2007) in France. Besides these authors, we based on Fedatto and Machado (2007) to understand the discursive functioning of the teacher-student relationship materialized in the analyzed scenes. And Milanez and Bittencourt (2012), who present the notion of film materiality.
\end{abstract}

Keywords: Discourse analysis. Film discourse. Teaching.

\section{Introdução}

1 Graduanda em Licenciatura em Letras/Inglês da Universidade Estadual de Goiás - UEG. E-mail: kamilaaquino@hotmal.com

2 Graduanda em Licenciatura em Letras/Inglês da Universidade Estadual de Goiás - UEG. E-mail: karlamurielle@hotmail.com

3 Docente da Universidade Estadual de Goiás - UEG. Doutoranda pelo Programa de Pós-graduação em Linguística pela Universidade do Estado de Mato Grosso - UNEMAT. E-mail: fernanda.fernandes@ ueg.br 
A relação professor e aluno é uma temática amplamente discutida. Pois se trata de uma relação que se constitui historicamente através de condições de produção específicas. Essas condições são atravessadas por questões sociais e ideológicas que ressignificam essa relação mostrando tanto deslocamentos quanto sentidos cristalizados produzindo efeitos na atualidade.

Para este trabalho, a partir dessa temática, buscamos compreender como as posições professor e aluno (re) significam as práticas de ensino e aprendizagem analisando os filmes $O$ Clube do Imperador dirigido por Michael Hoffman (2002) e O Sorriso de Monalisa sob direção de Mike Newell (2004), que possuem professores como personagens centrais.

Por isso, analisar filmes sobre esta temática, permite ter acesso também a concepções preexistentes de como deve ser o ensino, e ainda pode levantar questionamentos sobre os modos de como a educação na atualidade está estabelecida.

Para essa pesquisa adotamos como referencial teórico a Análise de Discurso de linha francesa, que nos permitirá compreender o funcionamento das posições-sujeito e como o discurso fílmico produz efeitos na produção dos sentidos. Essa concepção teórica tem como objeto o discurso, definido como "efeito de sentidos entre locutores" (ORLANDI, 2009, p.21). Desse modo, a Análise de Discurso compreende que “[...] diante de qualquer objeto simbólico, o homem, enquanto ser histórico, é impelido a interpretar, ou em outras palavras, a produzir sentidos" (ORLANDI, 1995, p. 44).

\section{Análise de discurso e discurso pedagógico}

A Análise de Discurso (AD) é uma teoria que busca a compreensão dos sujeitos e dos sentidos, sendo assim, o sentido, na perspectiva discursiva, é efeito produzido pela inscrição da língua na história e essa inscrição só pode ser vista através da língua, através dos objetos simbólicos, enquanto lugar de materialização da ideologia.

A Análise de Discurso é uma disciplina que permite trabalhar com outros objetos simbólicos que levam à produção dos sentidos, pois, “[...] é na prática material significante que os sentidos se atualizam, ganham corpo, significando particularmente" (ORLANDI, 1995, p. 35).

Desse modo, temos como objetivo analisar os efeitos das diferentes posições-sujeitos na relação entre professor e aluno em dois filmes, que dizem sobre a prática docente através de seus personagens, considerando não apenas a materialidade linguística como também as relações com diferentes materialidades (a imagem, o signo verbal, a sonoridade), pois são 
diferentes posições do sujeito que se produzem (ORLANDI, 1995), como observamos nos filmes analisados.

Nessa direção, a questão da imagem, para Pêcheux (2007) é discutida de outra forma sendo pensada enquanto não transparente, mas como uma "[...] imagem opaca e muda, quer dizer aquela da qual a memória "perdeu" o trajeto de leitura" (p. 55), permitindo, portanto, a análise dessa materialidade, pois como objeto simbólico, produz efeitos dos/para os sujeitos.

Com base em Orlandi (2009), podemos dizer que a linguagem é muito mais do que um sistema de comunicação usado pelo homem para expressar seus sentimentos e ideias através da escrita e fala; a produção da linguagem une-se de dois grandes processos: o polissêmico aquele que faz com que a palavra possua vários significados, e o parafrástico que permite a repetição, os sentidos cristalizados, mas que estão em constante batimento, pois através desses processos que os sentidos são produzidos.

Para a autora, a análise de discurso pode-se dizer que é uma região privilegiada, pois o discurso pode ser visto como persistente no modo de produção da linguagem.

Conforme Orlandi (2009, p.27): “As palavras mudam de sentido ao passares de uma formação discursiva para outra. Assim, não são somente as intenções que determinam o dizer." Os sentidos são produzidos numa relação com a história e a ideologia, é a interpelação ideológica que constitui os sujeitos e sentidos materializados na língua. Por isso, essa relação língua-história-ideologia constitui o sujeito.

Nessa direção, de acordo com Orlandi (2007), o sujeito não é o sujeito empírico, o sujeito é sempre “[...] 'posição' entre outras [...] é a posição que deve e pode ocupar todo indivíduo para ser sujeito do que diz" (p.49).

Assim, relacionado ao sistema de ensino, a posição sujeito tem haver com um poder da metalinguagem que o professor utiliza. Desse modo, para a autora, o Discurso Pedagógico possui como característica a autoridade, colocando o professor na posição daquele que ensina e do aluno, daquele que aprende. Segundo Orlandi (2009, p.31): "Pelo lado do aluno (nessa caracterização do DP), há aceitação exploração dessas representações que fixam o professor como autoridade e a imagem do aluno que se representa o papel de tutelado".

Para Orlandi (2009), para haver mudanças, o ensino deve compreender que mais "[...] do que informar, explicar ou mesmo persuadir, ensinar aparece como inculcar" (ORLANDI, 2009, p.17, grifos da autora). Dessa forma, o processo de ensino-aprendizagem só é possível quando o sujeito passa a interagir com outros, criando assim um campo de novos espaços de significação. 
Do ponto de vista do autor (professor) uma maneira de colocar de forma polêmica e construir seu texto, seu discurso, de maneira a expor a efeitos e sentidos possíveis, e deixar um espaço para a existência do ouvinte sujeito. Isto é deixar claro um espaço para o outro (o ouvinte) dentro do discurso e construir a própria possibilidade de ele mesmo (locutor) se colocar ouvinte. E saber ser ouvinte do próprio texto e do outro. (ORLANDI, 2009, p.32).

A linguagem nesse contexto adquire uma importância, tanto o professor quanto o aluno são sujeitos com habilidades e competências para atribuir significados as práticas discursivas num ambiente de interação.

Orlandi (2009) informa sobre o ensino, partindo da suposição de que se poderiam distinguir três tipos de discurso, em seu funcionamento discurso lúdico, discurso polêmico e discurso autoritário.

Para Orlandi (2009), o discurso lúdico é aquele em que o seu objeto se mantém presente enquanto tal e os interlocutores se expõem a essa presença.

O discurso polêmico mantém a presença do seu objeto, sendo que os participantes não se expõem, mas ao contrario procuram dominar o seu referente, dando-lhe uma direção, indicando perspectivas particularizantes pelas quais se olha e se o diz [...] No discurso autoritário, o referente está "ausente "oculto" pelo dizer; não há realmente interlocutores, mas um agente exclusivo. [...] Esse discurso recusa outra forma de ser que não a linguagem (ORLANDI, 2009, p. 15-16)

Nesse caso, coloca em funcionamento a figura do professor como o único detentor do conhecimento presente no discurso autoritário, pois a metodologia utilizada não envolve a participação dos interlocutores, ou seja, o ensino baseia-se em aulas onde os alunos tem o papel apenas de absorver o que é ensinado.

Da mesma forma, Fedatto e Machado (2007) falam sobre essa relação através da institucionalização das posições professor e aluno.

A relação professor-aluno na escola é um tema político: instaura um conflito de sentidos. Esse conflito poder ser entendido como questionamento que entra em cena pelo fato de ser a escola uma forma-histórica que institucionaliza a relação da sociedade com o conhecimento e suas formas de repetição. (FEDATTO, MACHADO, 2007, p. 9)

Para que ocorra o bom desempenho do ensino-aprendizagem as duas partes interessadas, professor e aluno precisam trabalhar em conjunto, o professor na condição de mediador do conhecimento e o aluno como aprendiz. 
Nessa perspectiva, Fedatto e Machado (2007) mostram que a relação professor-aluno passa pela constituição de várias posições sujeitos, principalmente, referente ao professor. Segundo as autoras,

Somos, como sujeitos de linguagem, atravessados por todos esses dizeres em relação ao professor, ao aluno, ao que é uma aula. Ocupando a posição de professor, vez ou outra (vez em todas!), falaremos a partir dessas diversas posições. São as materializações da constituição de nossa história. (FEDATTO, MACHADO, 2007, p. 14)

São as posições sujeito professor e aluno que se constituem em condições de produção específicas.

\section{A linguagem cinematográfica e a produção de sentidos}

Para refletir sobre o processo de ensino e aprendizagem na relação professor e aluno, foram selecionados dois filmes que tratam da educação. Os filmes são $O$ Sorriso de Monalisa e Clube do Imperador. Nestes filmes pode-se observar como o papel docente pode (ou não) marcar a vida dos discentes, pode produzir efeitos através da linguagem cinematográfica.

De acordo com Martin (2005), não há como dizer que o cinema não é arte. Mesmo havendo muita crítica, o autor considera que o cinema possui uma beleza, e é socialmente “[...] a mais importante e a mais influente da nossa época" (MARTIN, 2005, p. 17). Mesmo assim, ou por causa disso, o autor explica porque o cinema é visto de forma negativa. A isso ele explica através de três características: fragilidade, futilidade, facilidade.

Segundo Martin (2005, p. 17-18)

O cinema é fragilidade porque está ligado a um suporte material extremamente delicado e que acaba por se estragar com o uso; porque só a muito pouco tempo é que se encontra protegido pelo depósito legal e porque o direito moral dos criadores quase não é reconhecido; porque é considerado, antes de tudo uma mercadoria, é porque o possuidor tem o direito de destruir os filmes como muito bem entender [...] e porque em nenhuma das outras artes as contigências materiais tem tanta influência sobre a realidade dos criadores.

Os recursos para produzir um filme requerem um cuidado e dedicação a mais, pois são materiais sensíveis que pode ser perdido se não manusear cuidadosamente, já que é considerada apenas como uma mercadoria e em seus conteúdos possui o efeito de influenciar seus criadores como nenhuma outra arte. 
O cinema é futilidade porque é a mais jovem de todas as artes, nascida de uma vulgar técnica de reprodução mecânica da relidade; porque é considerado pela imensa maioria do público como um simples divertimento onde se vai sem cerimónia.[...] porque em nenhuma outra arte a concordância crítica é tão difícil de atingir e porque todas as pessoas se julgam autorizadas, tratando-se de cinema, a se considerarem juízes. (MARTIN, 2005, p.18).

Infelizmente o cinema não tem o seu reconhecimento adequado por ser a mais jovem das artes e pela facilidade em criticar uma obra já que qualquer pessoa pode se considerar apta a julgar.

Para Martin (2005, p. 18)

O cinema é facilidade porque se apresenta, a maioria das vezes, sob as aparências do melodrama, do erotismo ou da violência; porque consagra, em grande parte da sua produção, o triunfo da imbelicidade; porque é, nas mãos das potências econômicas que o dominam, um instrumento de embrutecimento. [...] Deste modo, vícios profundos contrariam o desenvolvimento estético do cinema; e, para além disso, um pecado original vergonhoso pesa sobre seu destino.

Ao mencionar a facilidade que se apresenta o cinema faz uma crítica, pois para produzir é necessária uma seleção de pré-requisitos, e a sociedade se ocupa em fazer delas uma grande obra.

Essas três características produzem efeitos quando se trabalha como material de análise como filmes que evocam toda uma memória sobre a produção e reprodução de imagens em movimento.

Para Milanez e Bittencourt (2012), trabalhar com materialidades específicas como os filmes, na perspectiva da análise de discurso, é buscar compreender a junção de diferentes materialidades, para produzir a materialidade fílmica.

Nessa direção, Lagazzi (2009) apresenta o conceito de "imbricação material” para pensar sobre como as diferentes materialidades devem ser compreendidas. Para a autora,

[...] a imbricação material se dá pela incompletude constitutiva da linguagem, em suas diferentes formas materiais. $\mathrm{Na}$ remissão de uma materialidade a outra, a não-saturação funcionando na interpretação permite que novos sentidos sejam reclamados, num movimento de constante demanda. (LAGAZZI, 2009, p. 70) 
Assim, o discurso fílmico é compreendido e analisado de em suas diferentes materialidades numa imbricação que as diferentes linguagens se significam mutuamente.

Por isso, Milanez e Bittencourt (2012, p. 8) mostram “[...] que os instrumentos para a discussão da materialidade do discurso fílmico e a construção de seus sentidos estão na própria história da Análise do Discurso", que permitem compreender não apenas a linguagem verbal, como também o não verbal, pois o discurso é efeito de sentido, nessa relação, as diferentes linguagens significaram numa relação com as condições de produção em que estão inseridas, na qual sujeito, história e ideologia significam pela linguagem, isto é, materializado na língua.

Nessa direção que Milanez eBittencourt (2012) refletem sobre o discurso fílmico. Mostrando o quanto a teoria discursiva permite um atravessamento histórico e social produzindo efeitos a partir de diferentes materialidades. Para os autores,

A teoria do discurso é feita de encontros, cruzamentos da história dos saberes, da produção de conhecimentos sobre o que pode ser enunciado, sobre o que é enunciável em momentos diferentes, construindo o discurso como um campo não apenas de lutas ou batalhas, mas de alianças e articulações que sobrepõem fatos do discurso. Essa presença discursiva pode apenas ser ouvida, vista, sentida, percebida por meio de materialidades. (MILANEZ, BITTENCOURT, 2012, p.10)

Dessa forma, o modo como o filme é produzido, como as imagens em movimento se significam e se constituem são pontos importantes para compreender o discurso fílmico.

Atrás da câmera há o olho que controla o que podemos ver e maneira como podemos ver. A materialidade fílmica, nesse sentido, é marcada primeiro de tudo pela força daquele que imprime seu olhar sobre uma imagem que chegará até nós com recortes e edições. Tomando a câmera como a extensão do corpo, serão as determinações corporais de um sujeito que vê o mundo por meio de maneira controlada e reduzida aos campos de visão dentro do enquadramento de uma lente. Por isso mesmo, qualquer posição de um sujeito é um olhar que conta, antes de tudo, o lugar que esse sujeito ocupa, tanto historicamente quanto fisicamente em relação à imagem capturada. Desse jeito, câmera, corpo e história são produções que não se dissociam e cuja existência produzirá as imagens que vemos em um filme. (MILANEZ, BITTENCOURT, 2012, 10-11)

Esse movimento, movimentos, recortes, seleção, mostram como as diferentes materialidades atuam para produzir efeitos. Assim, o filme representa um funcionamento discursivo que (re) significa diferentes práticas, a partir de diferentes perspectivas e condições de produção. 
Dessa forma, o modo como o cinema apresenta suas formas, sua linguagem implica no efeito produzido. Assim, analisar os filmes $O$ Sorriso de Monalisa e $O$ Clube do Imperador, é compreender através da linguagem cinematográfica como os sentidos são produzidos.

\section{Análise dos filmes: processos de constituição da relação professor-aluno}

Antes de iniciarmos a análise, apresentamos um resumo do enredo de cada filme.

Em Sorriso de Monalisa temos a personagem Katherine que vai dar aulas em uma escola só para meninas. Onde essas jovens tinha uma visão tradicional que mulheres eram formadas para ser boas esposas e mães, a professora inconformada com aquele modelo tradicional da escola que ela trabalhava, tenta mudar o pensamento de suas alunas e fazer com que enfrentem os desafios da vida.

O filme $O$ Clube do Imperador descreve como é o ensino do professor tradicional. $\mathrm{O}$ senhor Hundert é um típico docente autoritário e acredita que está moldando o caráter dos seus alunos. É professor de história ocidental, dá aulas sobre os gregos e romanos, para meninos da alta sociedade, tudo ocorria bem até que o filho do senador começa a estudar naquela escola, um rapaz arrogante devido a falta de carinho e atenção do pai, então o professor tenta mudá-lo, ajudando-o a ser uma pessoa melhor, conseguindo a sua confiança, mostrando que ele é capaz. Para que isso ocorra, é necessário que o docente forjasse uma classificação, para ter uma aproximação com o aluno e assim passar seu conhecimento, após algumas tentativas, ele não consegue mudar o caráter desse aluno.

Depois dos resumos, passamos as análises. Para compreender a relação docente e discente no filme, selecionamos algumas cenas para análise da posição-sujeito professor e posição-sujeito aluno.

A primeira cena retrata o primeiro momento de contato entre o professor Hundert e seus alunos. 


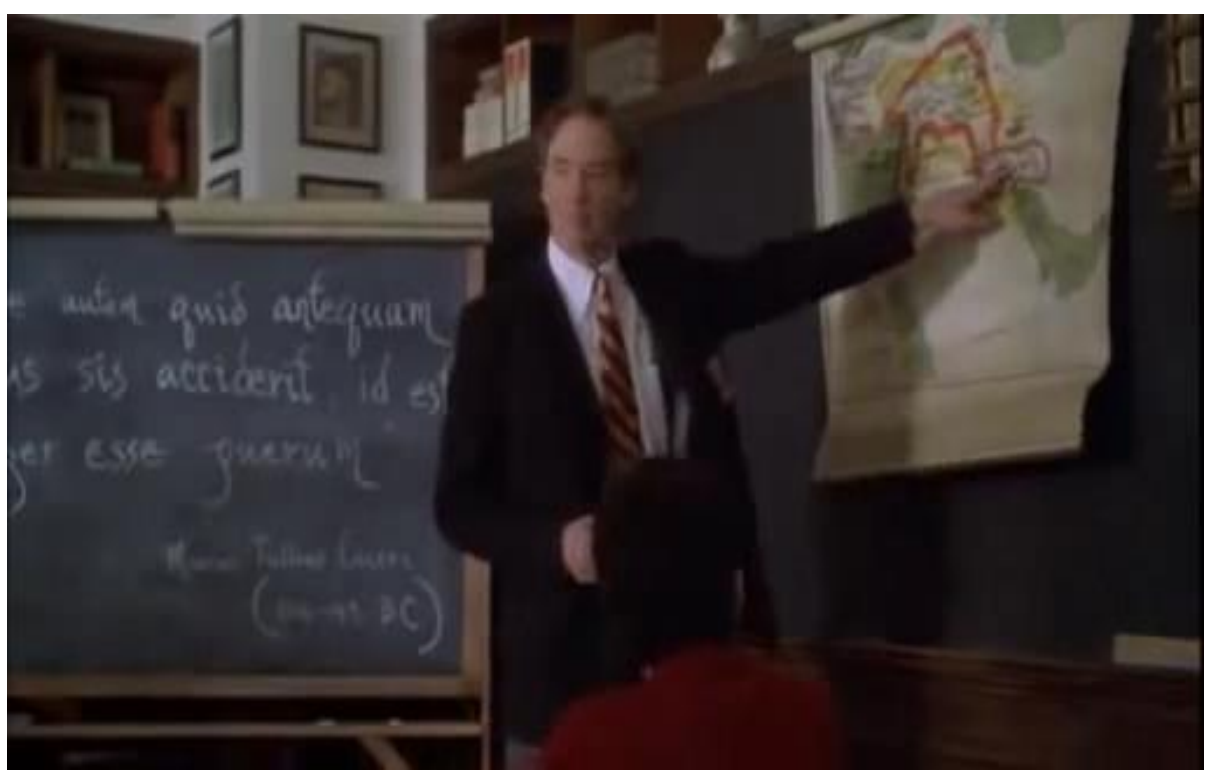

Figura 1: Imagem recortada do filme O Clube do Imperador (2002).

Nesta imagem observamos a posição professor é materializada através da postura, do ambiente, o quadro, o mapa, marcando que o docente precisa mostrar e expor o que está dizendo de forma que chame a atenção. Nisso, está o discurso da autoridade, da posição à frente dos alunos como se significasse que o caminho dá cada um deles dependesse de seguir ou não a aprendizagem do docente.

Percebe-se então que Hundert é um professor idealista, onde as sua aulas eram cheias de emoção e alegria, tentando mudar o caráter e a personalidades de seus alunos. Chamando sempre a atenção para grandes personagens da história.

Realizamos, portanto, uma comparação com a análise de Fedatto e Machado (2007) sobre o filme Sociedade dos poetas mortos. Nessa a análise as autoras mostram que:

As relações de poder em sala de aula não se deslocam e são sustentadas pelas imagens da posição-sujeito-professor como aquele que detém o conhecimento, que deve ser obedecido, e da posição-sujeito-aluno como aquele que deve aprender e obedecer ao professor. (FEDATTO, MACHADO, 2007, p. 10)

Nessa direção, os dois filmes se identificam, pois o professor é visto como o "profissional do saber", ou seja, o transmissor de conhecimento, que autoriza ao aluno como agir, como significar.

A fala desta cena em $O$ Clube do Imperador é:

Shutruk-Nahunte, rei, soberano da terra de Elam, destruidor de Sipar. Seus feitos não estão em nenhum livro de história, por quê? Porque ambição e 
conquista sem contribuição não tem significado. E qual será a contribuiução de vocês? Como a história se lembrará de vocês? Chucurte nahunt, totalmente esquecido. Diferentes destes homens que os rodeiam, Aristóteles, Cesar, Augusto, Platão, Cícero, Sócrates, gigantes da história, homens de profundo caráter. Homens cujas obras sobrepujaram suas e sobreviveram até as nossas vidas. A história deles é a nossa história. Eu sou o professor Hundert, bem-vindos a civilização ocidental, aos gregos e aos romanos. ${ }^{4}$

Observamos em sua fala a analogia e também a cobrança aos alunos em buscarem conhecimentos para sua formação de modo que sua contribuição faça a diferença para a sociedade.

Nesse recorte de imagem, observamos como a materialidade fílmica significa ao associar gestos, imagem, expressão, foco e a materialidade linguística. A postura do docente e sua formulação aos alunos se colocam como pontos fortes e marcantes para produzir efeitos nos alunos e no espectador.

Um aspecto que também levamos em consideração, nesse caso, são as condições de produção. Segundo Orlandi (2009), as condições de produção representam o sujeito e a situação. No caso da cena, por se tratar de uma escola para meninos e também para alunos da classe alta, futuros líderes mundiais, isso produz efeitos diferentes, se se tratasse de outras condições. Como por exemplo, se fosse alunos numa escola mista, numa escola somente para mulheres, numa escola católica, numa escola pública, etc., entre outras condições.

Assim, a fala do professor vem significar uma cobrança de que os alunos estejam preparados para alcançar o mesmo nível, ou próximo, dos grandes nomes da história. Eles devem fazer história, e suas condições sociais e econômicas podem propiciar isso. Isso se refere especificamente aos alunos que o professor Hundert ensina, fazem parte da elite da sociedade, portanto, são preparados para assumirem condições de destaque.

${ }^{4}$ Trecho transcrito da cena do filme. 


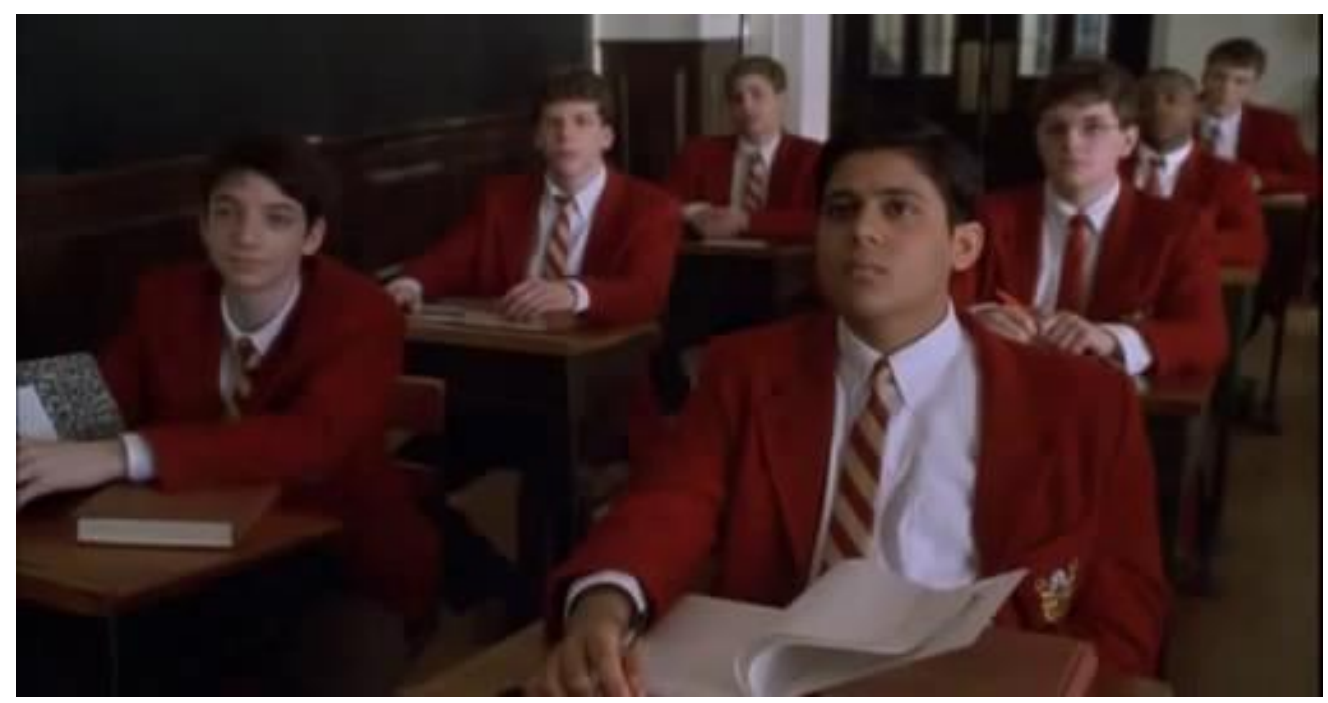

Figura 2: Imagem recortada do filme $O$ Clube do Imperador (2002).

$\mathrm{Na}$ segunda imagem, ainda na mesma cena, observamos a postura dos alunos, a seriedade, a organização das carteiras representam também a autoridade do professor. Esse modo de focalizar nos alunos produz ao mesmo tempo um olhar sobre a organização da sala e dos alunos de modo geral, mas também particulariza a ação de cada um, permitindo analisar como cada um recebe as palavras do docente.

Em um determinado trecho do filme ele afirma que "O fim depende do início", com essa concepção de ensino sua preocupação é transmitir o conhecimento, predomina mais a instrução que o debate; havendo mais teoria, do que prática; o aluno sendo mais passivo que ativo. Enfim o processo de aprendizagem é baseado em regras e normas.

Em O Sorriso de Monalisa também selecionamos a cena da primeira fala da personagem para as suas alunas. 


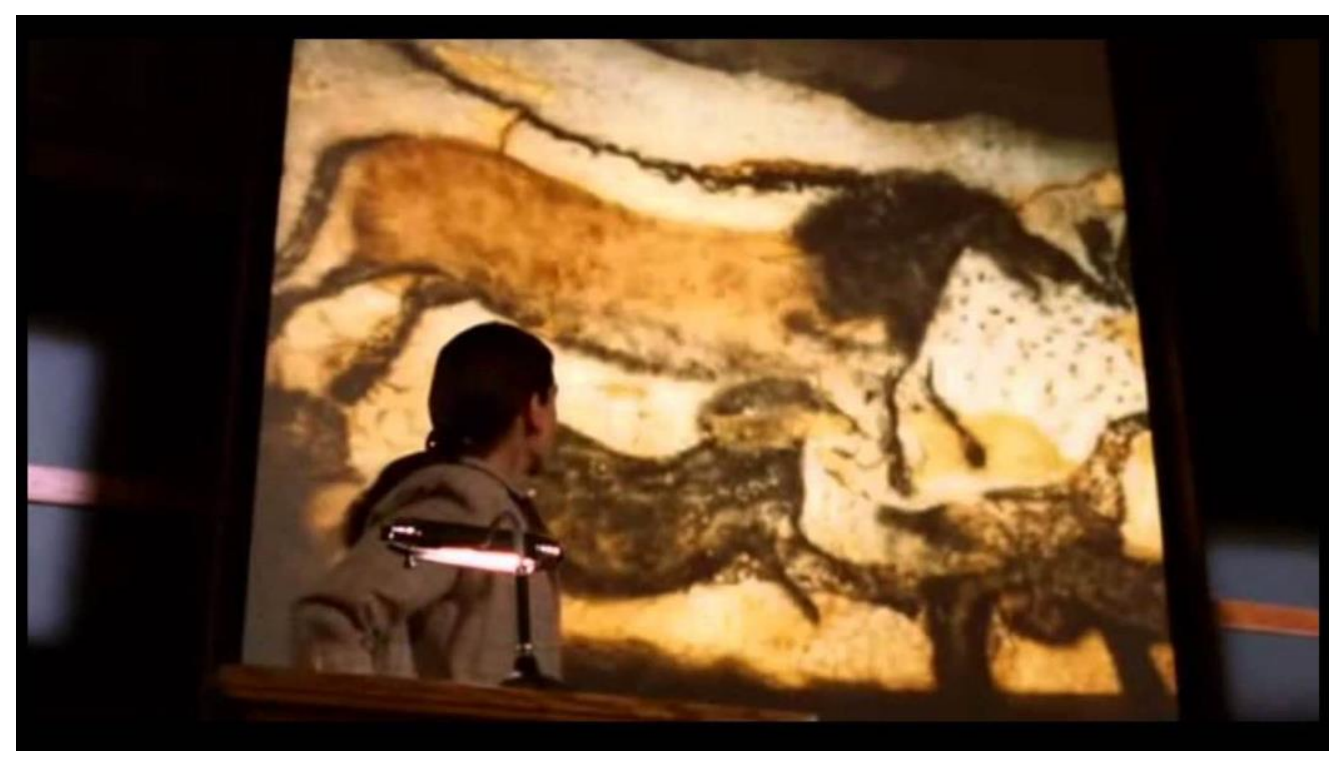

Figura 3: Imagem recortada do filme O Sorriso de Monalisa (2004)

$\mathrm{Na}$ imagem acima observamos a postura da docente, que à frente de suas alunas explica sobre a história da arte. Podemos dizer que a professora também assume a autoridade na sala, usa de recursos para dar visibilidade a sua explicação.

O discurso da autoridade significa as práticas docentes, mudando recursos e metodologias, a construção histórica e ideológica do papel docente continua a produzir seus efeitos.

Alguém pode apagar a luz? Suzzi de la Cortti....desde do início o homem sempre teve o impulso de criar a arte.....Alguém pode me dizer o que é...visão ferida Altamira Espanha 14 mil nos a.c.[...] Alguém de vocês teve aula de história da arte? Não......continua o próximo ...escriba sentada.[...] levantam as mãos quantas de vocês leram a apostila inteira, por favor. ${ }^{5}$

$\mathrm{Na}$ citação acima observamos que a professora apresentando as imagens da arte, e mesmo as alunas não tendo anteriormente a disciplina, as alunas reconheciam as imagens, porque haviam praticamente decorado a apostila.

Isso marca um funcionamento discursivo de que o conhecimento está materializado nos livros. Ao ver que as alunas decoraram a apostila a professora muda de postura. E faz que reflitam sobre a arte.

${ }^{5}$ Trecho transcrito da cena do filme. 


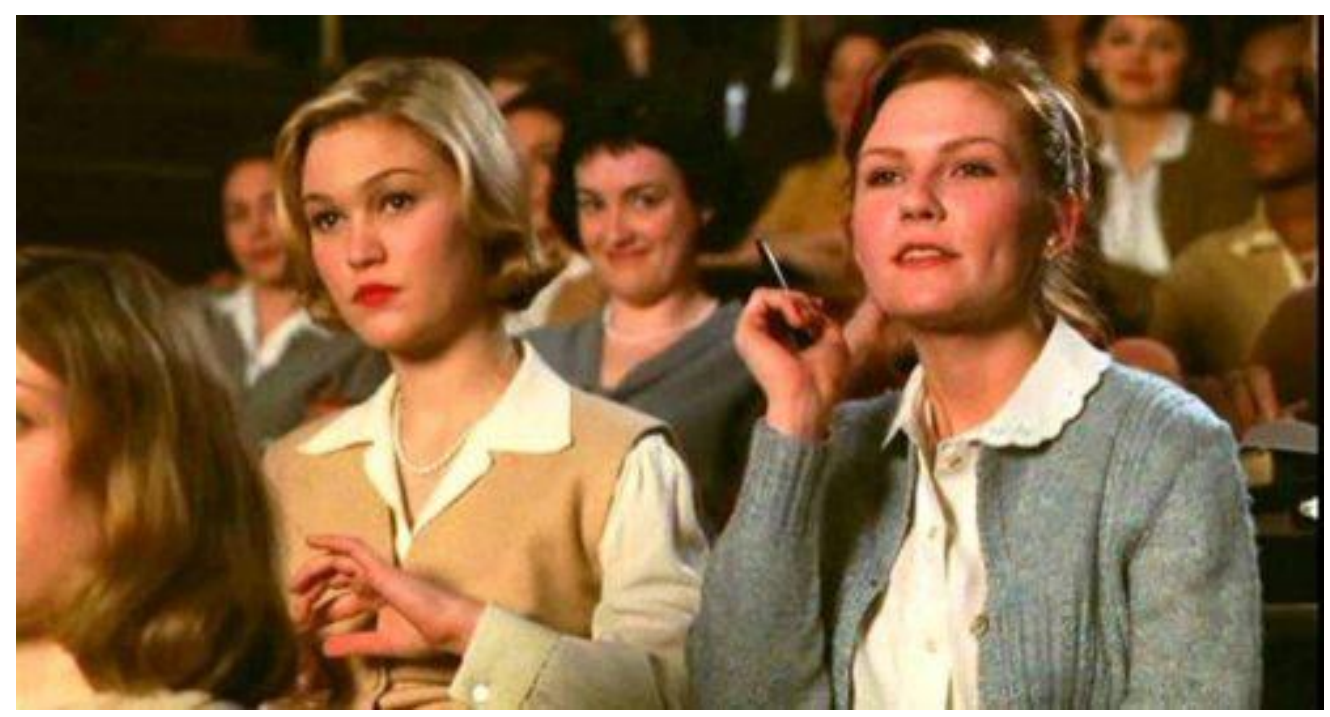

Figura 4: Imagem recortada do filme O Sorriso de Monalisa (2004)

$\mathrm{Na}$ imagem acima, observamos entre expectativa e indiferença em relação à aula. Como se o que a professora tivesse a dizer pudesse ser interessante, pela postura de uma das alunas, enquanto para a outra não fosse nada prático.

Como se trata de uma escola somente para mulheres. O que é colocado em funcionamento é a posição sujeito de professora que as pudesse auxiliar em conhecimentos específicos e necessários para a vida delas na atuação da casa, na família. Desse modo, compreender um pouco de arte faz parte de poder ser uma boa anfitriã. Cumpre um papel esperado pela figura feminina, nessas condições específicas. Mas que produzem efeitos na condição feminina até nos dias de hoje.

Em outro momento do filme $O$ Sorriso de Monalisa, Katherine diz ás alunas:

"Eu não sabia que exigindo excelência eu estaria desafiando os papéis para os quais vocês nasceram".

"Vamos abrir nossas mentes para ideias novas".

Essa fala coloca em funcionamento um olhar para o ensino que leva o aluno a refletir sobre suas práticas, seu conhecimento. Assim uma das principais funções do professor de toda e qualquer área: fazer o aluno pensar sobre algo e questioná-la.

\section{Considerações finais}

Os dois filmes retratam uma escola, uma de meninos e outras de meninas, apesar de que o tema foco são diferente um do outro, o essencial dos filmes é retratado no professor. 
Duas pessoas apaixonadas pelo seu serviço; tentam várias vezes estimular seus alunos de que são capazes.

Podemos comparar também os objetivos das escolas, enquanto em $O$ Clube do Imperador os alunos são preparados para assumir posições de prestígio na sociedade. Em $O$ Sorriso de Monalisa, as alunas são preparadas para atuar na casa, na família. Poderíamos, talvez, dizer que são preparadas para serem futuras esposas dos alunos da escola do filme $O$ Clube do Imperador, isso nos faz pensar sobre as questões femininas, referentes ao lar, família, e o quanto isso tem mudado, e como continua a produzir efeitos na atualidade.

Observamos que ambos os filmes têm na figura do professor seu papel central. Portanto, o professor, é o porta voz da ideologia da escola, pois ele centraliza o discurso em si próprio, nessa relação as posições sujeito e aluno são representadas pela/na figura de uma pessoa de autoridade que se significa na sua prática com os alunos, de acordo com as condições históricas e sociais que são materializadas pelo linguístico e discursivo.

\section{Referências}

FEDATTO, Carolina Padilha; MACHADO, Carolina de Paula. O muro, o pátio e o coral ou os sentidos no/do professor. In: BOLOGNINI, Carmen Zink (org.) Discurso e ensino: o cinema na escola. Campinas, SP: Mercado de Letras, 2007. p. 9-15.

LAGAZZI, Suzy. O recorte significante na memória. In: Anais III Seminário de Estudos da Análise de discurso. 2009.2 Disponível em: http://anaisdosead.com.br/3SEAD/Simposios/SuzyLagazzi.pdf. Acesso em 03 nov. 2017.

MARTIN, Marcel. A linguagem cinematográfica. Trad. Lauro António e Maria Eduarda Colares. Lisboa, Portugal: Dinalivvro, 2005.

MILANEZ, Nilton; BITTENCOURT, Joseane Silva. Materialidades da imagem no cinema: discurso fílmico, sujeito e corpo em A Dama De Ferro. Revista Movendo Ideias Vol. 17, N ${ }^{\circ}$ 2 - julho a dezembro de 2012 p.7-20. Disponível em: http://revistas.unama.br/index.php/Movendo-Ideias/article/view/631. Acesso em 02 nov. 2017

O CLUBE DO IMPERADOR. Direção de Michael Hoffman. Elenco: Kevin Kline, Emile Hirsch, Embeth Davidtz. Europa Filmes, 2002. 104 min. Dvd.

ORLANDI, Eni. P. A linguagem e seu funcionamento: as formas do discurso. Campinas: Pontes, 2005.

ORLANDI, E. P. Análise de discurso: princípios e procedimentos. $7^{\mathrm{a}}$ ed. Campinas, SP: Pontes Editores, 2007.

"Efeitos do verbal sobre o não-verbal". In: Rua: Revista do Núcleo de Desenvolvimento da Criatividade da UNICAMP - NUCREDI. Campinas, SP, Nº.1, março 1995. 
O SORRISO DE MONALISA. Direção de Mike Newell. Elenco: Julia Roberts. Kirsten Dunst. Julie Stiles. Columbia Pictures, 2004. 119 min. Dvd.

PÊCHEUX, Michel. Papel da memória. In: ACHARD, Pierre. Tradução e introdução José Horta Nunes $-2^{\mathrm{a}}$ ed. Campinas, SP: Pontes Editores, 2007. 